\title{
Chlorophyllin e6-mediated photodynamic therapy inhibits proliferation and induces apoptosis in human bladder cancer cells
}

\author{
ZHIYUAN ZHUO ${ }^{1}$, ZHENYU SONG $^{1}$, ZHE MA $^{1}$, YUANFANG ZHANG ${ }^{2}$, \\ GUOXIONG XU ${ }^{3}$ and GANG CHEN ${ }^{1}$ \\ ${ }^{1}$ Department of Urology, Jinshan Hospital, Fudan University, Shanghai 201508; \\ ${ }^{2}$ Department of Urology, Huashan Hospital, Fudan University, Shanghai 200040; \\ ${ }^{3}$ Center Laboratory, Jinshan Hospital, Fudan University, Shanghai 201508, P.R. China
}

Received September 5, 2018; Accepted February 11, 2019

DOI: 10.3892/or.2019.7013

\begin{abstract}
Patients with non-muscle invasive bladder cancer (NMIBC) frequently relapse following surgery due to incomplete resection and chemoresistance, highlighting the importance of developing novel therapeutic strategies that mechanistically assist in eradicating the residual tumor. The aim of the present study was to evaluate the anticancer effect of chlorophyllin e6-mediated photodynamic therapy (e6-PDT) and its potential mechanisms by using monolayer cells or multicellular tumor spheroid models of human bladder cancer cells (T24 and 5637). The results revealed that e6-PDT exhibited significant cytotoxicity in the T24 and 5637 cells of these two models as detected by the Water-Soluble Tetrazolium Salts-1 and CellTiter-Glo Luminescent Cell Viability assays, respectively. Cell migration and invasion capacities decreased markedly following e6-PDT. In addition, the cells following e6-PDT exhibited typical morphological changes of apoptosis as detected by fluorescence microscopy with 4',6-diamidino-2-phenylindole staining and transmission electron microscopy. A greater number of apoptotic cells were observed post-e6-PDT by flow cytometry. The expression levels of poly(adenosine diphosphate-ribose) polymerase (PARP) and B-cell lymphoma 2 protein were decreased, while cleaved PARP was increased, significantly following e6-PDT as determined by western blotting. The level of intracellular reactive oxygen species (ROS) was increased, while
\end{abstract}

Correspondence to: Dr Gang Chen, Department of Urology, Jinshan Hospital, Fudan University, 1508 Longhang Road, Shanghai 201508, P.R. China

E-mail: chgan305@163.com

Dr Guoxiong Xu, Center Laboratory, Jinshan Hospital, Fudan University, 1508 Longhang Road, Shanghai 201508, P.R. China E-mail: guoxiong.xu@fudan.edu.cn

Key words: chlorophyllin, photodynamic therapy, multicellular tumor spheroids, reactive oxygen species, superoxide dismutase the activity of superoxide dismutase (SOD) was decreased, significantly in e6-PDT-treated cells. Thus, the novel e6-PDT exhibits prominent photo-cytotoxicity effect and the induction of apoptosis was probably due to the inhibition of SOD activity and the generation of ROS. These results indicate that chlorophyllin e6 is an effective photosensitizer and that e6-PDT may have a therapeutic application for the treatment of bladder cancer.

\section{Introduction}

Bladder cancer is a common urological malignancy threatening public health globally and is ranked the ninth most frequently-diagnosed cancer in the world (1). According to the American Cancer Society, there were an estimated 81,190 new cases and 17,240 fatalities in the US in 2018 (2). Human bladder cancer can be classifieds into 3 types: Non-muscle invasive bladder cancer (NMIBC), muscular invasive bladder cancer and metastatic bladder cancer (3). NMIBC accounts for $\sim 75 \%$ of newly diagnosed cases (4). It has been reported that the 5-year recurrence and progression rates of NMIBC were $50-70$ and $10-30 \%$, respectively (4). The current primary treatment for NMIBC is transurethral resection followed by intravesical chemotherapy or intravesical immunotherapy with Bacillus Calmette-Guerin (BCG) (5). However, it cannot completely overcome the severe recurrence and progression, thereby resulting in bladder cancer to be the most expensive cancer per patient among all types of cancer (6-8). Notably, intravesical instillation of BCG may cause some undesirable side effects, including lower urinary tract symptoms, hematuria and bladder contracture (9). Therefore, it is imperative to develop more effective therapeutic strategies that could assist in eradicating residual tumor and obviate such problems against NMIBC.

Photodynamic therapy (PDT) has emerged as an attractive and promising therapeutic modality used in the treatment of malignant tumors as well as non-neoplastic diseases (10). PDT utilizes the characteristics of malignant cells which can selectively absorb and retain photosensitizer (PS). Following the introduction of a photosensitizing agent to the human body, the 
lesion is irradiated with a specific wavelength of light to activate the PS. With the presence of oxygen, the activation leads to the production of reactive oxygen species (ROS), which in turn causes tumor cells death $(11,12)$. It has been demonstrated that natural antioxidants/phytochemicals can act as pro-oxidants, which produce free radicals and cytotoxic ROS, cause oxidative stress and activate the inflammatory responses in the cells (13). Catalyzing metals, including transition metals, non-transition metals and metalloids, serve an important role in this process (14). Some natural plant substances can act as PSs in which the pro-oxidative potential can be potentiated by absorption of visible light (15). PSs are activated to initially form the excited singlet state, followed by a transition to the long-lived excited triplet state. This triplet state can undergo photochemical reactions in the presence of oxygen to form ROS (including singlet oxygen) that can serve as a tool for the destroying of unwanted cells (16). PSs can promote the production of cytotoxic ROS, leading to programming cell death by activating the mitochondrial caspase pathway (through disruption of the electron transport chain and consequent loss of the mitochondrial membrane potential) and other cell signaling pathways $(16,17)$. PSs thus represent a critical factor for the effectivity of anticancer therapy. Numerous studies have revealed that PDT can be effective in several types of tumors, with minimal invasiveness, high selectivity, negligible systemic toxicity and low risk of resistance (18-21). Furthermore, various studies have demonstrated that PDT is effective and safe as an alternative therapeutic strategy for NMIBC (22-24). Chlorophyllin e6 is a novel PS that we developed recently (25). It is one of the second-generation PSs derived from chlorophyll in green plants (25). Chlorophyllin e6 possesses the characteristics of an ideal PS, such as high purity and stability, low production cost, minimal toxicity without light irritation and appropriate optical properties. However, the function of chlorophyllin e6-mediated PDT (e6-PDT) in bladder cancer and its potential mechanisms remain largely unknown.

Multicellular tumor spheroids (MCTSs) are the most commonly used three-dimensional (3D) cultured models in tumor research (26). MCTSs refer to spherical aggregates of tumor cells that can be obtained through a variety of physical methods, including liquid overlay, hanging drop and magnetic levitation (26). Traditionally, the in vitro study of tumor biological behavior is predominantly performed with a 2-dimensional (2D) monolayer-cell model, whereas in vivo experiments are frequently performed with an experimental animal model. However, the monolayer cell culture technique may sometimes lead to incorrect results during drug screening, which can cause a high failure rate in clinical trials (27). By contrast, MCTSs can closely imitate the cell-cell and cell-matrix interactions that frequently occur in the native tumor microenvironment, which can be overlooked in 2D culture conditions (26). Therefore, MCTSs exhibit multiple cellular characteristics relevant to in vivo solid tumors, including the stereoscopic architecture, physiochemical gradients of oxygen and nutrients, gradients of cell proliferation and drug resistance (28).

In the present study, the phototoxic effect of e6-PDT in monolayer cells and MCTS models of human bladder cancer was investigated, including cellular morphological and functional changes, and the potential mechanisms underlying e6-PDT treatment.

\section{Materials and methods}

Chlorophyllin e6 preparation and spectroscopic analysis. Chlorophyllin e6 was developed on the basis of our patent specification (no. CN 200510024984.8), which was described in our previous study (25). The absorption spectra of chlorophyllin e6 with different concentrations (10 and $100 \mu \mathrm{g} / \mathrm{ml})$ between 400 and 1,100 $\mathrm{nm}$ were measured using an ultraviolet and visible spectrophotometer (752PC; Shanghai Spectrum Instruments Co., Ltd., Shanghai, China).

Cell lines and monolayer cells culture. Human bladder cancer cell lines T24 and 5637 were purchased from the Shanghai Institutes of Biological Sciences (Chinese Academy of Sciences, Shanghai, China) and cultured in RPMI-1640 medium (Sigma-Aldrich; Merck KGaA, Darmstadt, Germany) supplemented with $10 \%$ fetal bovine serum (FBS; Gibco; Thermo Fisher Scientific, Inc., Waltham, MA, USA) and $1 \%$ streptomycin-gentamycin solution (Thermo Fisher Scientific, Inc.). Cells were incubated at $37^{\circ} \mathrm{C}$ in a humidified atmosphere containing $5 \% \mathrm{CO}_{2}$. T24 and 5637 cells were plated in 96-well plates (Thermo Fisher Scientific, Inc.) with $1 \times 10^{4}$ cells $/ 100 \mu 1$ medium/well or in 6 -well plates containing $30 \times 10^{4}$ cells $/ 2 \mathrm{ml} \mathrm{medium/well.}$

e6-PDT on monolayer cells. T24 and 5637 cells were grown in 96-well plates $\left(1 \times 10^{4}\right.$ cells in $100 \mu \mathrm{l} /$ well $)$ or 6 -well plates (30x $10^{4}$ cells in $2 \mathrm{ml} /$ well) at $37^{\circ} \mathrm{C}$ for $24 \mathrm{~h}$. Once the cells reached $\sim 80 \%$ confluence, the culture medium was removed and different concentrations of chlorophyllin e6 $(0.5$, 1 and $2 \mu \mathrm{g} / \mathrm{ml}$ ) were administrated and the cells were incubated in the dark at $37^{\circ} \mathrm{C}$ for $2 \mathrm{~h}$. Once the culture medium was replaced, the cells were irradiated using a $635 \mathrm{~nm}$ semiconductor laser (BWT Beijing Ltd., Beijing, China) at a power density of 10 or $40 \mathrm{~mW} / \mathrm{cm}^{2}$. The duration of laser exposure was 100 or $200 \mathrm{sec}$ to obtain different laser energies. The laser exposure for $100 \mathrm{sec}$ at $10 \mathrm{~mW} / \mathrm{cm}^{2}$ laser power density generated $1 \mathrm{~J} / \mathrm{cm}^{2}$ laser energy. The laser exposure for $100 \mathrm{sec}$ at $40 \mathrm{~mW} / \mathrm{cm}^{2}$ generated $4 \mathrm{~J} / \mathrm{cm}^{2}$ laser energy. The laser exposure for $200 \mathrm{sec}$ at $40 \mathrm{~mW} / \mathrm{cm}^{2}$ generated $8 \mathrm{~J} / \mathrm{cm}^{2}$ laser energy.

Based on the different treatment conditions, T24 and 5637 monolayer cells were divided into 9 groups as follows: Three control groups (blank control, e6 alone control and laser alone control) and six experiment groups with different PS concentrations and laser energies applied $\left(0.5 \mu \mathrm{g} / \mathrm{ml}+1 \mathrm{~J} / \mathrm{cm}^{2}\right.$; $0.5 \mu \mathrm{g} / \mathrm{ml}+4 \mathrm{~J} / \mathrm{cm}^{2} ; 1 \mu \mathrm{g} / \mathrm{ml}+1 \mathrm{~J} / \mathrm{cm}^{2} ; 1 \mu \mathrm{g} / \mathrm{ml}+4 \mathrm{~J} / \mathrm{cm}^{2}$; $2 \mu \mathrm{g} / \mathrm{ml}+1 \mathrm{~J} / \mathrm{cm}^{2}$; and $2 \mu \mathrm{g} / \mathrm{ml}+4 \mathrm{~J} / \mathrm{cm}^{2}$ ). Each group had 3 replicates.

MCTS culture and growth characteristics. The present study typically optimized the liquid overlay technique to acquire single and stable 3D MCTSs with spherical structure and uniform size. The 96-well plates were coated with agar gel, which prevents cell attachment and results in the cells suspension aggregating into cell spheroids. Briefly, $1 \%$ agar gel (Sigma-Aldrich; Merck KGaA) was processed by high-pressure-steam sterilizing and melted in microwaves prior to use. The hot agar solution was immediately pipetted into a 96-well plate $(65 \mu \mathrm{l} /$ well) and cooled for $\sim 30$ min to solidify. Next, T24 and 5637 single cell suspensions were added to each 
well with different initial seeding densities (500-10,000/well) and cultured in an incubator for $24 \mathrm{~h}$. The culture medium was changed every 2 days the growth characteristics of spheroids were observed and recorded. Only one MCTS formed per well at $24 \mathrm{~h}$ with a spherical structure and uniform size was selected for further experiments. The field microscopy images of MCTSs at different initial seeding densities were acquired using an inverted microscope (IX73; Olympus Corporation, Tokyo, Japan). The diameters of each spheroid were measured simultaneously using CellSens Life Science Imaging Software (CellSens Dimension 1.12; Olympus Corporation, Tokyo, Japan).

e6-PDT on MCTSs. T24 and 5637 cells were cultured in agar-coated 96-well plates $(2,000$ cells in $200 \mu \mathrm{l} /$ well $)$ for $24 \mathrm{~h}$ to form MCTSs. Spheroids were incubated for $3 \mathrm{~h}$ with chlorophyllin e6 and then irradiated in the same manner as the monolayer cells above, but the PS concentration $(2.5,5$ and $10 \mu \mathrm{g} / \mathrm{ml}$ ) and laser energy $\left(4 \mathrm{~J} / \mathrm{cm}^{2}, 8 \mathrm{~J} / \mathrm{cm}^{2}\right)$ used were much higher for MCTSs compared with monolayer cells in order to achieve effective results. MCTSs were also divided into 9 groups: Three control groups (blank control, e6 alone control and laser alone control) and six experiment groups $\left(2.5 \mu \mathrm{g} / \mathrm{ml}+4 \mathrm{~J} / \mathrm{cm}^{2} ; 2.5 \mu \mathrm{g} / \mathrm{ml}+8 \mathrm{~J} / \mathrm{cm}^{2} ; 5 \mu \mathrm{g} / \mathrm{ml}+4 \mathrm{~J} / \mathrm{cm}^{2}\right.$; $5 \mu \mathrm{g} / \mathrm{ml}+8 \mathrm{~J} / \mathrm{cm}^{2} ; 10 \mu \mathrm{g} / \mathrm{ml}+4 \mathrm{~J} / \mathrm{cm}^{2}$; and $\left.10 \mu \mathrm{g} / \mathrm{ml}+8 \mathrm{~J} / \mathrm{cm}^{2}\right)$. Each group had 3 replicates.

Morphology observation and cell viability assay. The morphological changes of monolayer cells and MCTSs in the different treatment groups following $24 \mathrm{~h}$ of incubation were observed and recorded using an inverted microscope (IX73; Olympus Corporation).

Monolayer cell viability was measured using the Water-Soluble Tetrazolium salts-1 (WST-1; Roche Diagnostics, Indianapolis, IN, USA) assay in accordance with the manufacturer's instructions. Following photodynamic treatment and further incubation for $24 \mathrm{~h}$, the culture medium was displaced and $10 \mu \mathrm{l}$ WST-1 solution combined with $100 \mu$ l serum-free RMPI-1640 medium were added into each well and incubated for $2 \mathrm{~h}$. The optical density (OD) value was determined at $450 \mathrm{~nm}$ using a microplate reader (Epoch; BioTek Instruments, Inc., Winooski, VT, USA).

MCTS cell viability was evaluated using a CellTiter-Glo Luminescent Cell Viability Assay (Promega Corporation, Madison, WI, USA), which determine the number of living cells based on quantitation of the amount of adenosine triphosphate (ATP) present. Following PDT and culture for an additional $24 \mathrm{~h}, 100 \mu \mathrm{l}$ CellTiter-Glo solution was directly mixed with the culture medium and incubated at room temperature for $20 \mathrm{~min}$. Following this, the luminescence intensity was recorded.

Cell colony formation assay. To further assess the long-term proliferative capacity of T24 and 5637 cells following e6-PDT treatment, a cell colony formation assay was performed. Cells were cultured in 6-well plates to conduct PDT and collected immediately following laser light irradiation. A cell suspension was inoculated into 6 -well plates with 500 cells $/ 2 \mathrm{ml}$ medium/well. The culture medium was changed every 2 days. Following 7 days of growth, colonies were visible. Subsequently, the colonies were washed twice with phosphate-buffered saline (PBS; Nanjing KeyGen Biotech Co., Ltd., Jiangsu, China) and 4\% paraformaldehyde (Nanjing KeyGen Biotech Co., Ltd.) was applied to fix cells at room temperature for 15 min. Crystal violet (Sigma-Aldrich; Merck KGaA) was used to stain cells at room temperature for $30 \mathrm{~min}$. Following washing and removal of any extra dye, the colonies in different groups were photographed and the total number of colonies in each well were calculated.

Cell migration and invasion assay. The scratch wound healing assay was employed to measure cell migration capacity. Cells were treated with e6-PDT in 6-well plates and were scratched immediately by a pipette tip to form a wound. Cells were washed twice with PBS and then incubated with the serum-free RMPI-1640 medium. Images were captured at the time points of 0 and $24 \mathrm{~h}$ using an inverted microscope (IX73; Olympus Corporation) at a magnification of $\mathrm{x} 40$. The widths of each wound were quantified using CellSens Life Science Imaging Software (CellSens Dimension 1.12; Olympus Corporation).

Cell invasion capacity was evaluated using a Transwell assay. Firstly, the Matrigel (Corning Inc., New York, NY, USA) was diluted to $250 \mu \mathrm{g} / \mathrm{ml}$ and $100 \mu \mathrm{l}$ was coated on the upper chamber of a Transwell plate (Costar, Corning Inc.) for $4 \mathrm{~h}$ prior to use. Following this, the T24 cells $\left(3 \times 10^{4}\right)$ and 5637 cells $\left(4 \times 10^{4}\right)$ were suspended in serum-free RMPI-1640 medium. Control and e6-PDT treated cells were added into the upper Matrigel-coated chamber, while the lower chamber was filled with $800 \mu \mathrm{l}$ of RMPI-1640 medium supplemented with $10 \%$ FBS. Following $48 \mathrm{~h}$ of incubation at $37^{\circ} \mathrm{C}$, the cells remaining above the membrane were carefully wiped out. The lower chamber with the invading cells was fixed with $4 \%$ paraformaldehyde at room temperature for $15 \mathrm{~min}$ and then dyed with crystal violet at room temperature for $30 \mathrm{~min}$. Images of the invaded cells in different groups were captured using an inverted microscope (IX73; Olympus Corporation) at a magnification of $\mathrm{x} 200$. The number of the cells were counted.

4',6-diamidino-2-phenylindole (DAPI) staining. Following e6-PDT treatment in T24 and 5637 cells for $12 \mathrm{~h}$, nuclear staining was performed with $2 \mu \mathrm{g} / \mathrm{ml}$ DAPI solution at $37^{\circ} \mathrm{C}$ for $10 \mathrm{~min}$. DAPI can attach to the minor groove of double-stranded DNA, forming a stable compound with 20-fold fluorescence enhancement (29). A fluorescent microscope (IX73; Olympus Corporation) at a magnification of x400 was utilized for observation and analyses.

Transmission electron microscopy (TEM). Monolayer and MCTS models of T24 and 5637 cells were processed by e6-PDT. Following PDT treatment for $12 \mathrm{~h}$, cells were collected and fixed with $2.5 \%$ glutaraldehyde at $4^{\circ} \mathrm{C}$ overnight. Following this, cells were washed 3 times with $0.1 \mathrm{M}$ phosphate buffer for 15 min each and fixed with $1 \%$ osmic acid at room temperature for $2 \mathrm{~h}$. After washing another 3 times with $0.1 \mathrm{M}$ phosphate buffer, samples were dehydrated using a gradient concentration of ethanol and acetone, and then embedded with acetone and embedding resin as 2:1 at room temperature for $4 \mathrm{~h}$, following 1:2 at room temperature overnight, and finally with pure embedding resin at $37^{\circ} \mathrm{C}$ for $3 \mathrm{~h}$. Samples were solidified and cut into ultrathin sections with a thickness 
of 50-60 nm, then stained with 3\% uranyl acetate at room temperature for $10 \mathrm{~min}$ and lead citrate at room temperature for a further $5 \mathrm{~min}$. Alteration in the intercellular structures, including the nucleus and mitochondria, were observed and photographed by TEM (Philips CM20; Philips Healthcare, Amsterdam, The Netherlands).

Cell apoptosis analysis by flow cytometry. The Annexin Vfluorescein isothiocyanate (FITC)/propidium iodide (PI) Apoptosis Detection kit (BD Biosciences, Franklin, NJ, USA) was applied to evaluate apoptosis of bladder cancer cells following e6-PDT. T24 and 5637 cells were seeded in 6-well plates $\left(30 \times 10^{4}\right.$ cells/well $/ 2 \mathrm{ml}$ medium) and cultured overnight. Following this, cells were treated with $0.5,1$ and $2 \mu \mathrm{mol} / 1$ of chlorophyllin e 6 for $2 \mathrm{~h}$ and $4 \mathrm{~J} / \mathrm{cm}^{2}$ of laser irradiation. All cells were collected using EDTA-free trypsin (Nanjing KeyGen Biotech Co., Ltd.) and washed twice with PBS. The cells were dissociated with $500 \mu \mathrm{l}$ Binding Buffer and then $5 \mu \mathrm{l}$ PI with $5 \mu \mathrm{l}$ Annexin V-FITC was added. Following incubation at room temperature for $10 \mathrm{~min}$, the mixtures were immediately studied using a flow cytometer (Beckman Coulter, Inc., Brea, CA, USA). The results were analyzed using Gallios Cytometry List Mode Data Acquisition and Analysis Software (Gallios Cytometer 1.2; Beckman Coulter, Inc.).

Western blot analysis. T24 and 5637 cells were split into 4 groups, including the blank control, the e6 alone, the laser alone and the e6-PDT groups $(2 \mu \mathrm{g} / \mathrm{ml}$ chlorophyllin e6 combined with $4 \mathrm{~J} / \mathrm{cm}^{2}$ laser irradiation). At 2, 12 and $24 \mathrm{~h}$ post-processing, cells were lysed and harvested using SDS buffer (Beyotime Institute of Biotechnology, Haimen, China) supplemented with $1 \%$ phenylmethanesulfonyl fluoride (Beyotime Institute of Biotechnology) and 1\% phosphatase inhibitors (Beyotime Institute of Biotechnology). The protein concentrations of the lysate were detected using a BCA Protein Assay Kit (Thermo Fisher Scientific, Inc.). The proteins (20 $\mu \mathrm{g} /$ lane) were separated on $10 \%$ gels via SDS-PAGE and were transferred to a polyvinylidene difluoride membrane (EMD Millipore, Billerica, MA, USA). Following blocking with $5 \%$ non-fat powdered milk at room temperature for $1 \mathrm{~h}$, the membrane was incubated with a primary antibody at $4^{\circ} \mathrm{C}$ overnight. The primary antibodies used in the present study were poly(adenosine diphosphate-ribose) polymerase (PARP) rabbit antibody (1:2,000 dilution; cat. no. 9542), B-cell lymphoma 2 (Bcl-2) mouse antibody (1:2,000 dilution; cat. no. 15071) and $\beta$-actin mouse antibody (1:5,000 dilution; cat. no. 3700) (all from Cell Signaling Technology, Inc., Danvers, MA, USA). Following washing 3 times with Tris-buffered saline Tween-20 for $10 \mathrm{~min}$ each, a secondary anti-mouse IgG HRP-linked antibody (1:3,000 dilution; cat. no. 7076) or anti-rabbit IgG HRP-linked antibody (1:3,000 dilution; cat. no. 7074) (all from Cell Signaling Technology, Inc.) was added to bind the specific primary antibody at room temperature for $1 \mathrm{~h}$. Finally, the protein bands were visualized using Immobilon Western Chemiluminescent HRP Substrate (EMD Millipore) and analyzed using a Tanon 4500 Gel Imaging System (Tanon Science and Technology Co., Ltd., Shanghai, China).

Intracellular ROS detection. The 2',7'-dichlorofluorescein diacetate (DCFH-DA) reagent (Sigma-Aldrich; Merck KGaA) was used to measure the production levels of intracellular ROS in T24 and 5637 cells following e6-PDT. Once permeated into cells, the non-fluorescent compound can react with ROS and transform into DCF, which possesses higher fluorescence that can be detected. Following e6-PDT treatment for $2 \mathrm{~h}, 10 \mu \mathrm{mol} / \mathrm{l}$ of DCFH-DA solution was added into the cells for $30 \mathrm{~min}$ at $37^{\circ} \mathrm{C}$, shielded from light. Subsequently, cells were collected and examined by flow cytometry to calculate the proportion of cells with DCF fluorescence.

Measurement of superoxide dismutase (SOD) activity. The activity of SOD was detected using a SOD Assay Kit-WST purchased from Dojindo Molecular Technologies, Inc. (Shanghai, China). The experiment was performed according to the manufacturer's instructions. Following $2 \mathrm{~h}$ of treatment, T24 and 5637 cells were harvested using a cell scraper, separated by centrifugation and washed with PBS. Cells were resuspended in PBS and lysed on ice with an ultrasonic oscillator. The cell lysates were centrifuged at $10,000 \mathrm{xg}$ at $4^{\circ} \mathrm{C}$ for $15 \mathrm{~min}$ to prepare the sample solution. The sample solution or double distilled $\mathrm{H}_{2} \mathrm{O}$, WST working solution, dilution buffer or enzyme working solution were added sequentially into 96-well plates based on the protocol. The plate was put into an incubator at $37^{\circ} \mathrm{C}$ for $20 \mathrm{~min}$ and the $\mathrm{OD}$ values were measured at $450 \mathrm{~nm}$ using a microplate reader (BioTek Instruments, Inc.). The inhibition rate of WST was calculated based on the absorbance, which directly reflected the activity of SOD in the different groups.

Statistical analysis. Results were analyzed using Microsoft Excel 2017 (Microsoft Corporation, Redmond, WA, USA), SPSS version 22 (IBM Corp., Armonk, NY, USA), and GraphPad Prism 7 (GraphPad Software, Inc., La Jolla, CA, USA). Data were presented as the mean \pm the standard deviation. For multiple comparisons, one-way analysis of variance was used, followed by a post hoc test (two-sided Dunnett test which treats one group as a control group and compares all other groups against it). $\mathrm{P}<0.05$ was considered to indicate a statistically significant difference.

\section{Results}

Absorption spectra of chlorophyllin e6. The ultraviolet-visible absorption spectra revealed that chlorophyllin e 6 had 3 characteristic absorption peaks at wavelengths 558, 654 and $975 \mathrm{~nm}$ (data not shown). As the effective penetration depth of the laser light has a direct correlation with its wavelength and visible light is more convenient to perform PDT, the present study selected $654 \mathrm{~nm}$ as the excitation wavelength in the chlorophyllin e6-mediated photosensitization.

E6-PDT inhibits the viability of monolayer cells. The phototoxic effect of e6-PDT treatment in T24 and 5637 monolayer cells was assessed using a WST-1 assay. The OD values of each group were calculated and transformed into cell viability data. The morphological changes of T24 and 5637 monolayer cells were examined with an inverted microscope. Monolayer cells in the e6-PDT group exhibited cell shrinkage, vacuole formation and cell detachment from each other (Fig. 1A and B). In the T24 monolayer cells, the laser alone group and the 
A

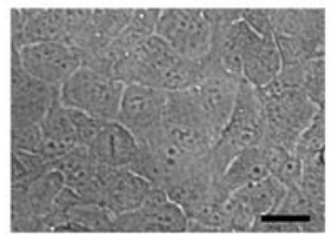

Blank control

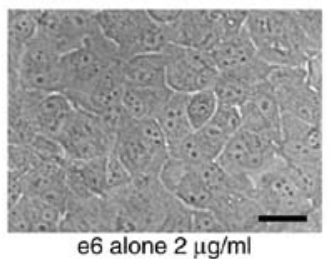

C

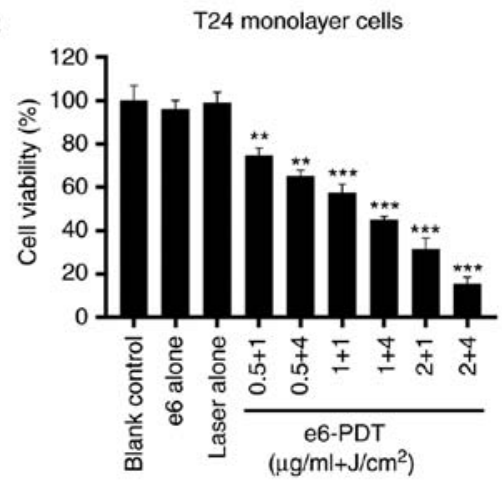

B

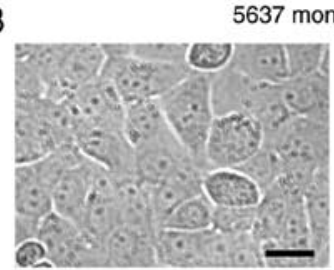

Blank control

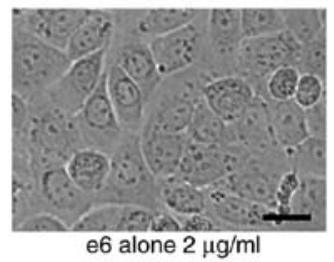

D

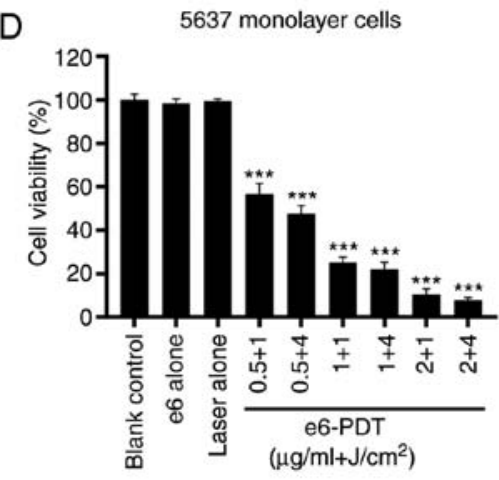

Figure 1. Phototoxic effect of e6-PDT in monolayer cells of T24 and 5637. (A and B) The morphological changes of T24 and 5637 cells were observed using an inverted microscope at $24 \mathrm{~h}$ following e6-PDT. Monolayer cells in the e6-PDT group exhibited cell shrinkage, vacuole formation and cell detachment from each other. Scale bar $=25 \mu \mathrm{m}$. (C and D) Cell viability of T24 and 5637 monolayer cells was measured using the Water Soluble Tetrazolium salts-1 assay ( $\mathrm{n}=3$ ). ${ }^{* * *} \mathrm{P}<0.01$ and ${ }^{* * *} \mathrm{P}<0.001$ vs. blank control group. e6-PDT, chlorophyllin e6-mediated photodynamic therapy.

chlorophyllin e6 alone group exhibited barely restrained cell viability when compared with the blank control group. The results also demonstrated that the e6-PDT groups exhibited a marked decrease in cell viability. The PDT effect was laser energy-dependent and chlorophyllin e6 dose-dependent. The cell viability following e6-PDT treatment with $0.5,1$ and $2 \mu \mathrm{g} / \mathrm{ml}$ chlorophyllin e6 plus 1 and $4 \mathrm{~J} / \mathrm{cm}^{2}$ laser irradiations in T24 monolayer cells was 74.77, 65.18, 57.65, 45.15, 31.52 and $15.43 \%$, respectively (Fig. 1C). A similar outcome was observed in the 5637 monolayer cells. The cell viability of each e6-PDT group in the 5637 monolayer cells was 56.65, $47.75,25.26,21.98,10.54$ and $7.73 \%$, respectively (Fig. 1D).

Growth characteristics of MCTSs. T24 and 5637 cells were cultured in agar gel-coated 96-well plates with different initial seeding densities $(500,1,000,2,500,5,000$ and 10,000 cells/well). The cells were spontaneously aggregated and formed 3D MCTSs within $24 \mathrm{~h}$. The spheroids grew gradually and the size increased. The two cell lines exhibited a distinctive pattern of spheroid growth. Spheroids derived from T24 cells grew faster than 5637 cell spheroids at different inoculum density, particularly in 500 cells and 1,000 cells. When the seeding number was 500 cells, the mean diameter of T24 cell spheroids increased from $186.08 \mu \mathrm{m}$ on day 1 to $559.51 \mu \mathrm{m}$ on day 11 , while the spheroids of 5637 cells increased from $132.07 \mu \mathrm{m}$ on day 1 to $239.83 \mu \mathrm{m}$ on day 11 (data not shown).
E6-PDT inhibits the viability of MCTSs. To overcome the poor penetration capacity of WST-1, the present study used a CellTiter-Glo Luminescent Cell Viability Assay to reflect the viability of MCTSs by detecting the content of ATP. The notable differences in viability indicated that T24 and 5637 MCTSs were more resistant to e6-PDT when compared with their corresponding monolayer cells, which indicated that MCTSs are closer to the tumor conditions in vivo.

The morphological change of T24 and 5637 MCTSs were recorded using an inverted microscope. MCTSs in the e6-PDT group exhibited destruction of spheroid structure and density reduction (Fig. 2A and B). In T24 MCTSs, the cell viability for e6-PDT treatment with $2.5,5$ and $10 \mu \mathrm{g} / \mathrm{ml}$ chlorophyllin e6 combined with 4 and $8 \mathrm{~J} / \mathrm{cm}^{2}$ light doses was $86.49,82.06,69.19$, $70.33,25.16$ and $2.43 \%$, respectively (Fig. 2C), while in 5637 MCTSs, the cell viability of each e6-PDT group was 102.97 , $88.43,76.89,63.06,38.58$ and $0.05 \%$, respectively (Fig. 2D). The laser alone group and the chlorophyllin e6 alone group did not exhibit notable inhibition of cell viability in T24 and 5637 MCTSs.

E6-PDT inhibits the proliferation of bladder cancer cells. A cell colony formation assay was performed to assess the effect of e6-PDT treatment on the long-term growth of the T24 and 5637 cell lines. It was observed that the number of colonies decreased significantly in e6-PDT treatment groups compared with the blank control group (Fig. 3A and B). In addition, no 
A

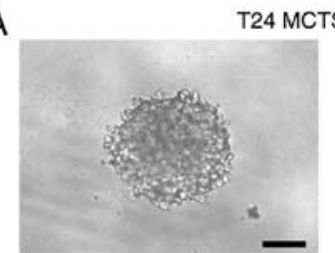

Blank control

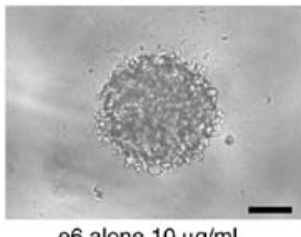

e6 alone $10 \mu \mathrm{g} / \mathrm{ml}$

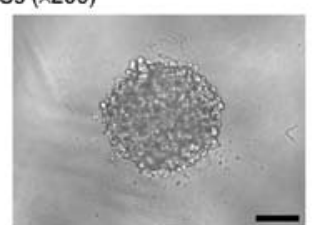

Laser alone $8 \mathrm{~J} / \mathrm{cm}^{2}$

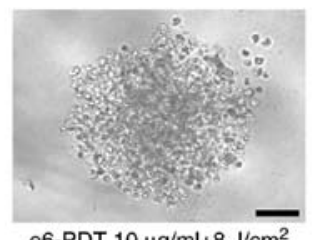

C

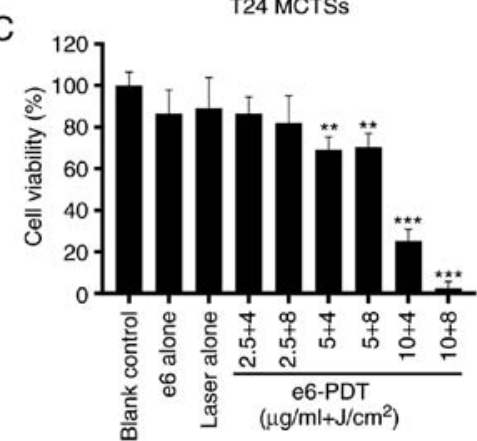

B

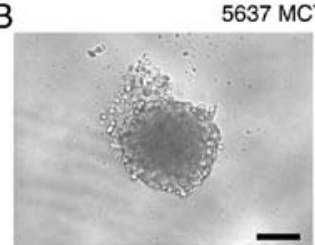

Blank control

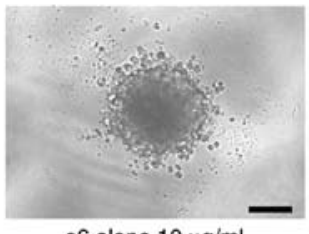

e6 alone $10 \mu \mathrm{g} / \mathrm{ml}$
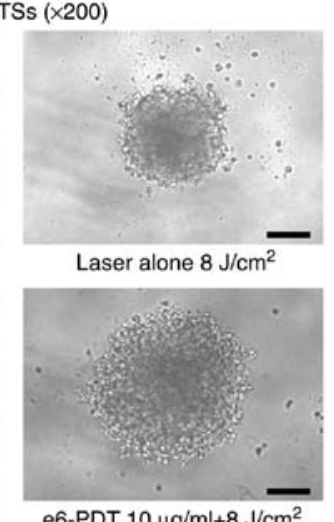

e6-PDT $10 \mu \mathrm{g} / \mathrm{ml}+8 \mathrm{~J} / \mathrm{cm}^{2}$

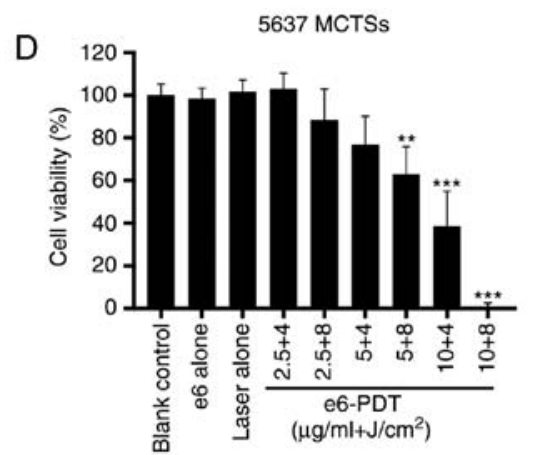

Figure 2. Phototoxic effect of e6-PDT in T24 and 5637 MCTSs. (A and B) Morphological changes of T24 and 5637 MCTSs were recorded using an inverted microscope at $24 \mathrm{~h}$ post-e6-PDT. MCTSs in the e6-PDT group exhibited destruction of spheroid structure and density reduction. Scale bar=100 $\mu \mathrm{m}$. (C and D) Cell viability of T24 and 5637 MCTSs was determined by the CellTiter-Glo assay ( $\mathrm{n}=3$ ). ${ }^{* *} \mathrm{P}<0.01$ and ${ }^{* * *} \mathrm{P}<0.001$ vs. blank control group. e6-PDT, chlorophyllin e6-mediated photodynamic therapy; MCTSs, multicellular tumor spheroids.

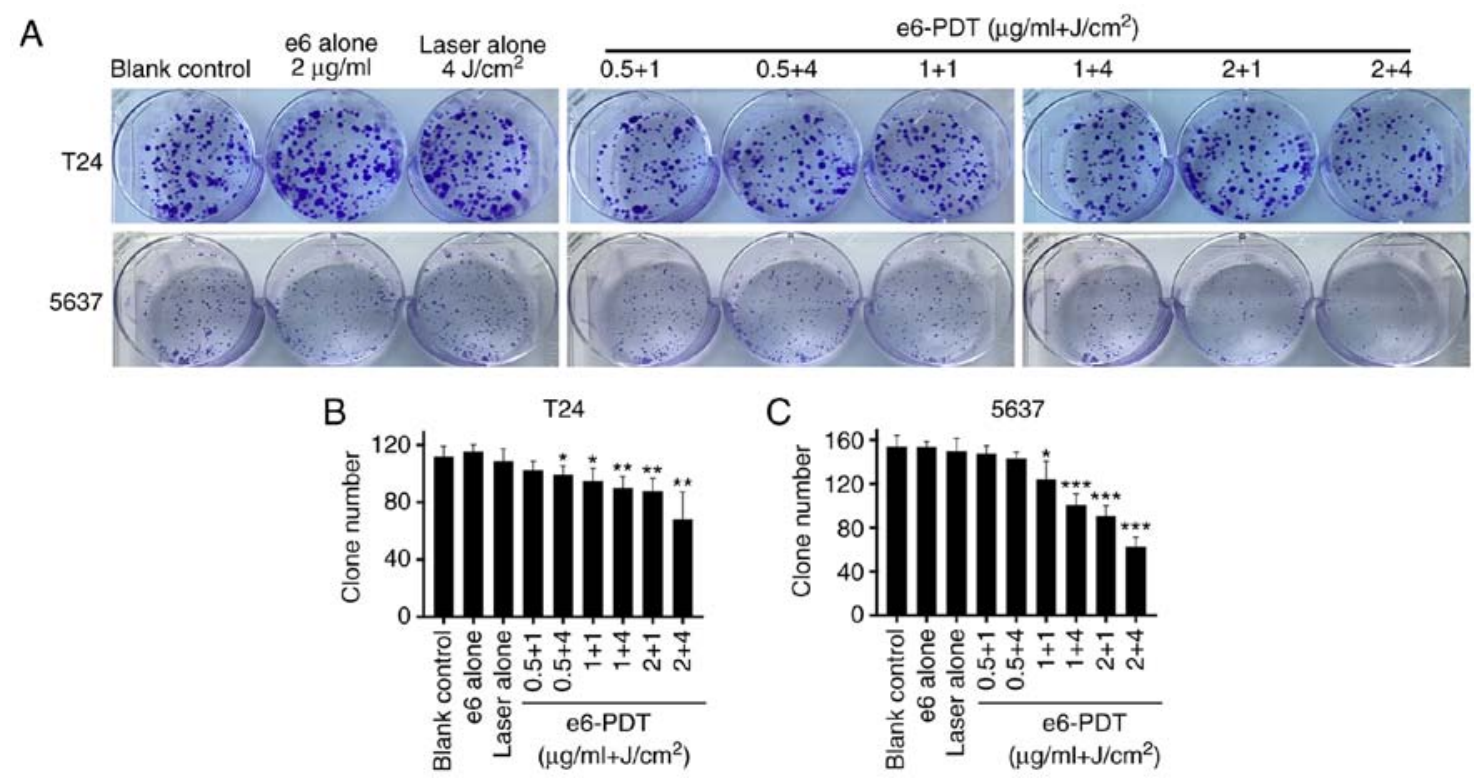

Figure 3. Inhibitory effect of e6-PDT on bladder cancer cell proliferation. (A) A cell colony formation assay was performed. (B and C) Effect of e6-PDT treatment on the long-term proliferation of T24 and 5637 cells was evaluated $(\mathrm{n}=4)$. ${ }^{*} \mathrm{P}<0.05,{ }^{* *} \mathrm{P}<0.01$ and ${ }^{* * *} \mathrm{P}<0.001$ vs. blank control group. e6-PDT, chlorophyllin e6-mediated photodynamic therapy.

statistically significant difference between the blank control group and the chlorophyllin e6 alone group or the laser alone group were revealed.

E6-PDT inhibits the migration and invasion of bladder cancer cells. The migration ability of T24 and 5637 cells following e6-PDT was evaluated using a wound-healing assay. Following $24 \mathrm{~h}$ of incubation, cells in the blank control group and e6 or laser alone group exhibited a similar migration distance. However, cells in the e6-PDT treatment groups exhibited significantly decreased migration into the wound in a chlorophyllin e6 dose-dependent manner (Fig. 4A-D). 

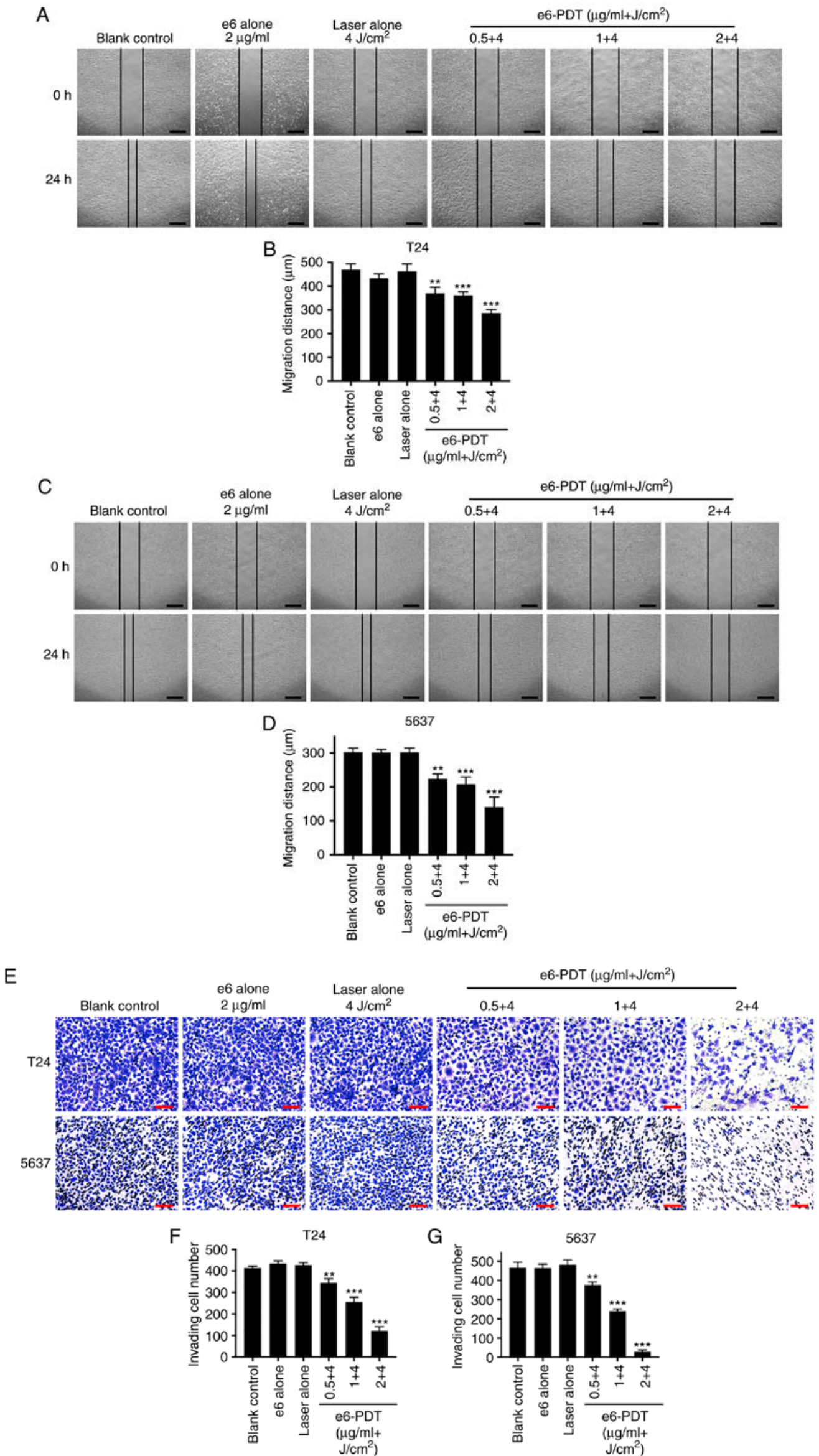

Figure 4. Inhibitory effect of e6-PDT on the migration and invasion of bladder cancer cells. A wound healing assay was applied to measure the migration ability of (A and B) T24 and (C and D) 5637 cells following e6-PDT. Images were captured at the 0 and 24 h time points and the widths of each wound were measured. Scale bar=500 $\mu \mathrm{m}$. (E) Cell invasion capacity of (F) T24 and (G) 5637 cells was evaluated using a Transwell assay. Scale bar=100 $\mu \mathrm{m}$. Migrated cells were photographed and quantified following $48 \mathrm{~h}(\mathrm{n}=3){ }^{* *} \mathrm{P}<0.01$ and ${ }^{* * *} \mathrm{P}<0.001$ vs. blank control group. e6-PDT, chlorophyllin e6-mediated photodynamic therapy. 


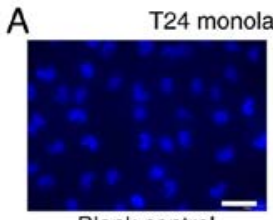

Blank control

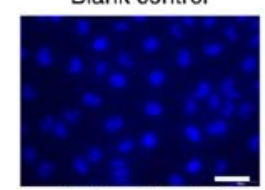

e6 alone $2 \mu \mathrm{g} / \mathrm{m}$

C

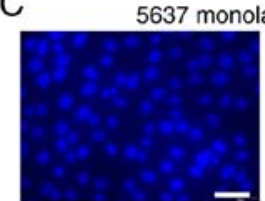

Blank control

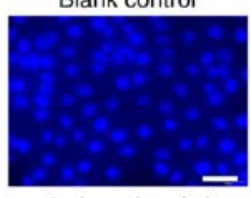

e6 alone $2 \mu \mathrm{g} / \mathrm{ml}$

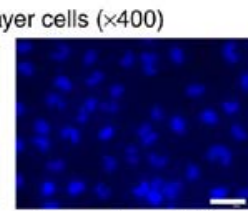

Laser alone $4 \mathrm{~J} / \mathrm{cm}^{2}$

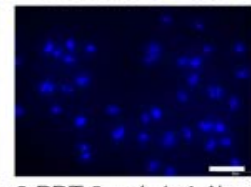

e6-PDT $2 \mu \mathrm{g} / \mathrm{ml}+4 \mathrm{~J} / \mathrm{cm}^{2}$

ayer cells $(\times 400)$

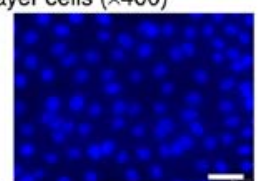

Laser alone $4 \mathrm{~J} / \mathrm{cm}^{2}$

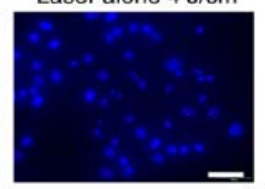

e6-PDT $2 \mu \mathrm{g} / \mathrm{ml}+4 \mathrm{~J} / \mathrm{cm}^{2}$

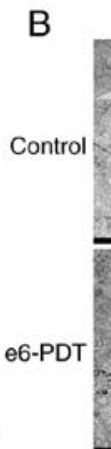

D

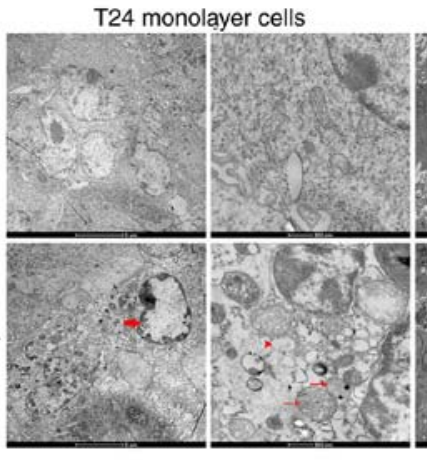

5637 monolayer cells

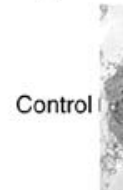

e6-PDT

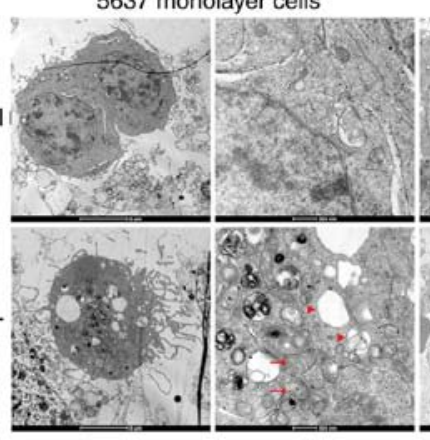

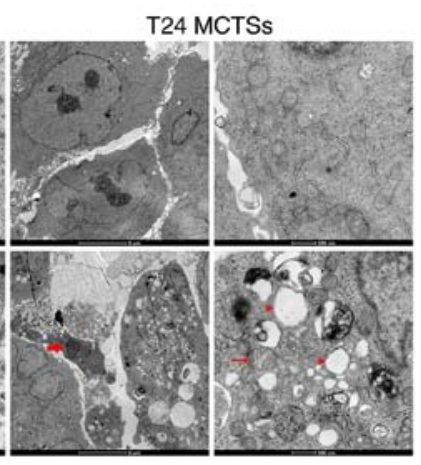

5637 MCTSs

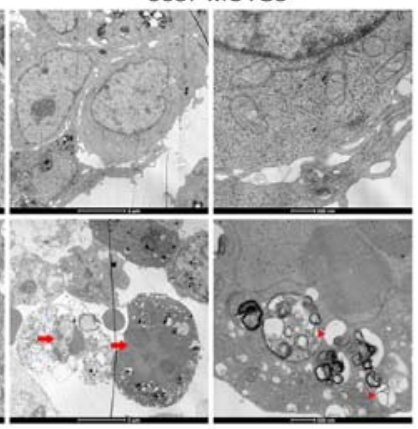

Figure 5. Morphological and ultrastructural changes of apoptosis. (A) Morphological alterations of the apoptotic nuclei of T24 monolayer cells following e6-PDT were assessed using DAPI staining. Scale bar=50 $\mu \mathrm{m}$. (B) Ultrastructural changes of T24 cells, monolayer cells and MCTSs, following e6-PDT were observed using TEM. (C) Morphological alterations of the apoptotic nuclei of 5637 monolayer cells following e6-PDT were assessed using DAPI staining. Scale bar=50 $\mu \mathrm{m}$. (D) Ultrastructural changes of 5637 cells, monolayer cells and MCTSs, following e6-PDT were observed and compared by TEM. DAPI staining revealed karyopyknosis and nuclear fragmentation in the e6-PDT group. TEM revealed chromatin condensation and edge accumulation (thick arrows), mitochondria swelling (thin arrows), and cytoplasm vacuolization (arrowheads) in the e6-PDT group (scale bar=5 $\mu \mathrm{m}$ on a left image and $500 \mathrm{~nm}$ on a right image in each cell type). e6-PDT, chlorophyllin e6-mediated photodynamic therapy; TEM, transmission electron microscopy; DAPI, 4'6-diamidino-2-phenylindole.

To further examine the effect of e6-PDT on cell invasion capacity, a Transwell assay was conducted. The number of invading cells through the membrane in e6-PDT treatment groups was significantly decreased when compared with the blank control group. In addition, no statistical difference was observed between the blank control group and the e 6 alone group or the laser alone group (Fig. 4E-G).

Morphological and ultrastructural changes in apoptotic cells. The morphological alterations of apoptotic nuclei in T24 and 5637 cells following e6-PDT were assessed with DAPI staining (Fig. 5). Cells in the e6-PDT group displayed more features of apoptotic nuclei, including karyopyknosis, nuclear fragmentation and chromatin condensation (Fig. 5A and C).

The present study further verified this finding by TEM. The ultrastructural changes of T24 and 5637 cells, both monolayer cells and MCTSs, following e6-PDT were observed. The connection between cells was loose and the amount of pseudopodia structure was vast in MCTSs when compared with monolayer cells. Furthermore, following treatment with e6-PDT, cells exhibited characteristic apoptotic changes in morphology, including cell shrinkage, pseudopodia disappearance, chromatin condensation, mitochondria swelling, and cytoplasm vacuolization (Fig. 5B and D).

E6-PDT increases the apoptotic rate of bladder cancer cells. Apoptosis was quantified by flow cytometry with Annexin V-FITC/PI double staining. The results revealed that e6-PDT treatment markedly enhanced the apoptotic rate of T24 and 5637 cells in a chlorophyllin e6 dose-dependent manner (Fig. 6A-C). Treatment with $0.5,1$ and $2 \mu \mathrm{g} / \mathrm{ml}$ of chlorophyllin e6 plus $4 \mathrm{~J} / \mathrm{cm}^{2}$ light dose resulted in a $12.83,14.60$ and $31.50 \%$ increase in the apoptosis of T24 cells, respectively, and a 7.07, 12.67 and $30.77 \%$ increase in the apoptosis of 5637 cells, respectively. These were significantly higher than the blank control group, which exhibited only $9.70 \%$ apoptosis in T24 cells and $5.37 \%$ in 5637 cells. In addition, the apoptosis rate was not statistically different in the chlorophyllin e6 alone group nor the laser alone group of both types of cells.

Expression levels of apoptosis-associated proteins following e6-PDT. Western blot analysis was applied to measure the expression levels of apoptosis-associated proteins PARP, cleaved PARP and Bcl-2 at 2, 12 and $24 \mathrm{~h}$ post-treatment. Compared with the blank control group, the expression levels of PARP and Bcl-2 were decreased, whereas the cleaved PARP expression level was increased, in the e6-PDT treatment group at 12 and $24 \mathrm{~h}$ (Fig. 6D and E). No significant differences were detected between the 3 control groups, and T24 and 5637 cells had similar results.

E6-PDT induces ROS generation in bladder cancer cells. To investigate whether cell apoptosis post-e6-PDT occurs through the generation of ROS, the present study detected intracellular ROS levels using DCFH-DA reagent. Based on the fluorescence intensity of DCF detected by flow cytometry, the results demonstrated that intracellular ROS levels were increased significantly in the e6-PDT groups when compared 
A
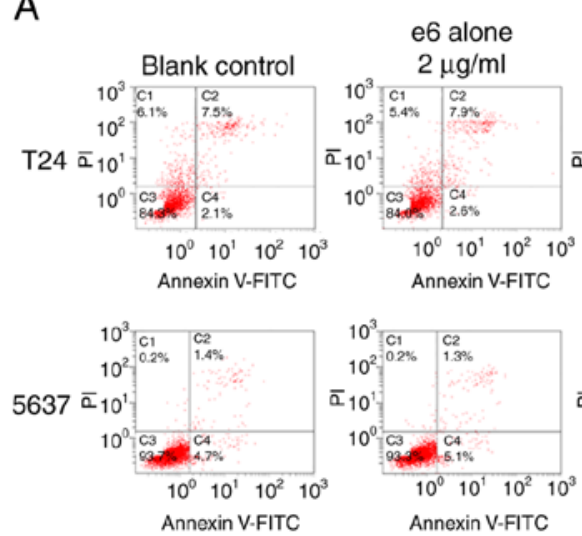

B

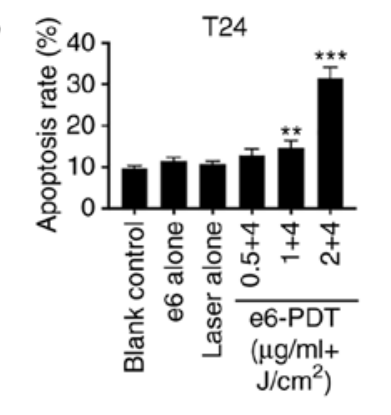

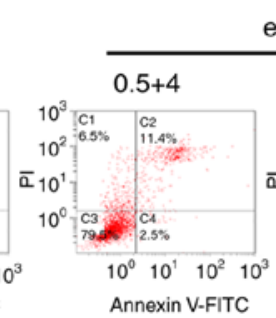

e6-PDT $\left(\mu \mathrm{g} / \mathrm{ml}+\mathrm{J} / \mathrm{cm}^{2}\right)$
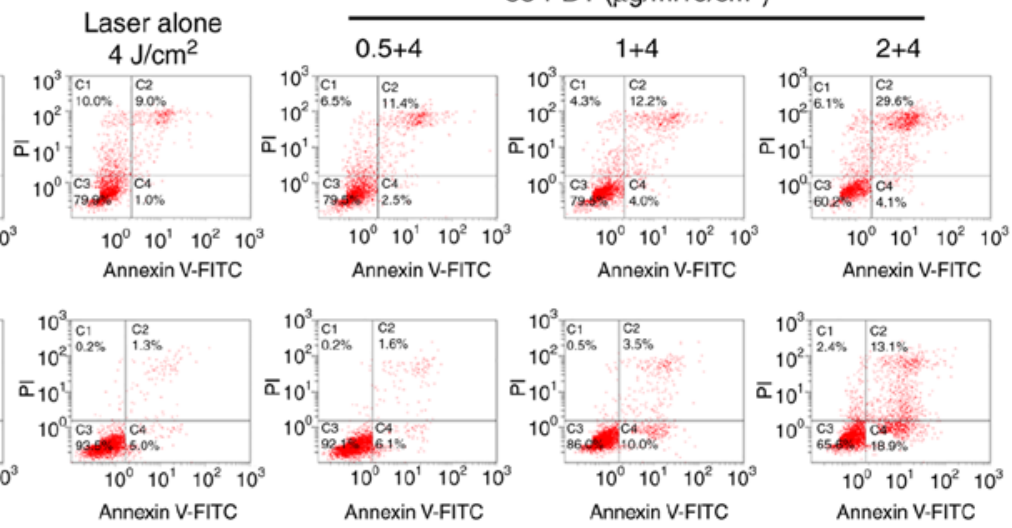

C

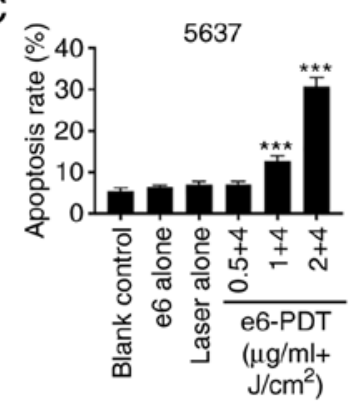

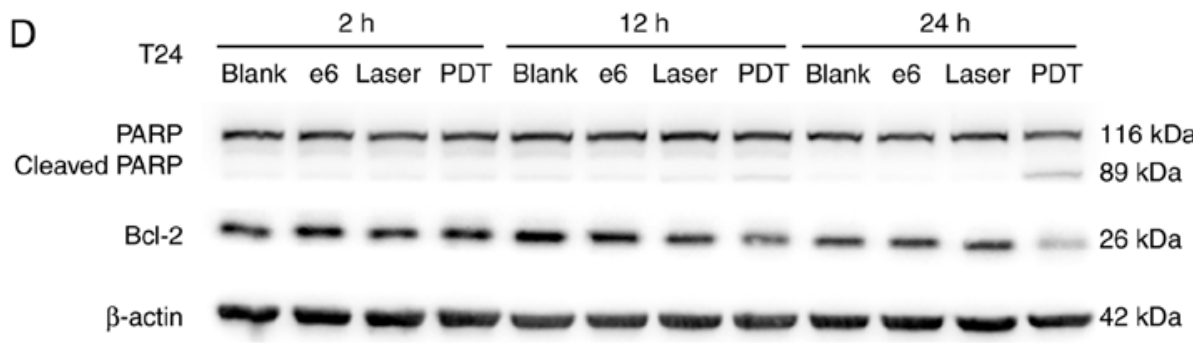

E

$5637 \frac{2 \mathrm{~h}}{\text { Blank e6 Laser PDT }} \frac{12 \mathrm{~h}}{\text { Blank e6 Laser PDT Blank e6 Laser PDT }}$

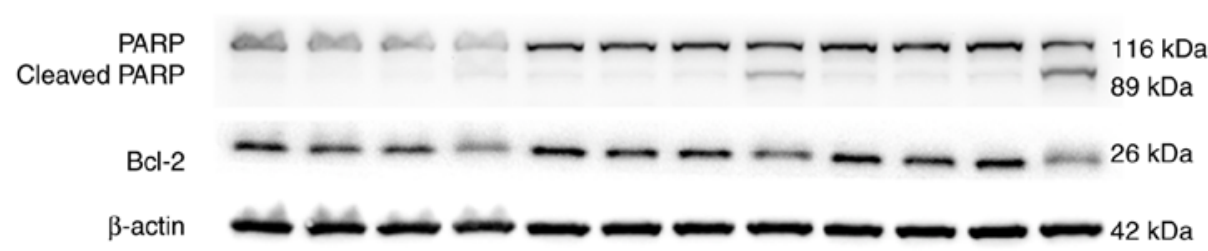

Figure 6. Induction of apoptosis by e6-PDT in bladder cancer cells. (A) Apoptotic rate of (B) T24 and (C) 5637 cells following e6-PDT was quantified by flow cytometry with Annexin V-FITC/PI double staining $(\mathrm{n}=3) .{ }^{* *} \mathrm{P}<0.01$ and ${ }^{* * * *} \mathrm{P}<0.001$ vs. blank control group. Western blot analysis was performed to detect the expression of the apoptosis-associated proteins PARP, cleaved PARP and Bcl-2 in (D) T24 and (E) 5637 cells at 2, 12 and 24 h post-treatment. e6-PDT, chlorophyllin e6-mediated photodynamic therapy; PARP, poly(adenosine diphosphate-ribose) polymerase; Bcl-2, B-cell lymphoma-2; FITC, fluorescein isothiocyanate; PI, propidium iodide.

with the blank control group (Fig. 7A-C). These effects were chlorophyllin e6 dose-dependent. The ROS levels were also marginally elevated in the chlorophyllin e6-alone and laser alone groups. This may be due to the exposure of light during the detection. Furthermore, the ROS levels were elevated to higher levels in the e6-PDT groups when compared with the chlorophyllin e6-alone or laser alone groups. T24 and 5637 cells exhibited similar outcomes. These results indicated that the generation of intracellular ROS may be the possible reason for e6-PDT-induced apoptosis.
E6-PDT inhibits SOD activity in bladder cancer cells. To determine the mechanism of ROS generation, the present study measured the activity of SOD in T24 and 5637 cells at $2 \mathrm{~h}$ post-e6-PDT. The absorbance of each group at $450 \mathrm{~nm}$ was converted into the SOD activity (inhibition rate of WST). The results revealed that the activity of SOD was significantly lower in the e6-PDT groups compared with the blank control group, which presented chlorophyllin e6 dose dependence (Fig. 7D and E). However, the chlorophyllin e6 alone and laser alone did not significantly affect SOD activity. 
A

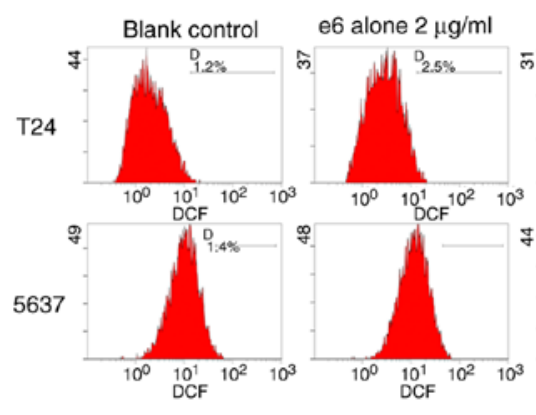

B

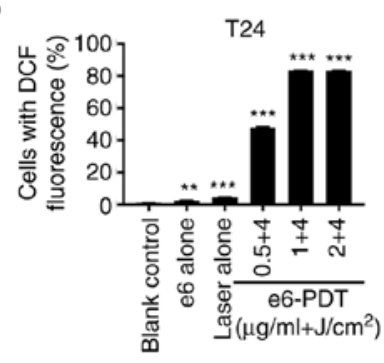

D

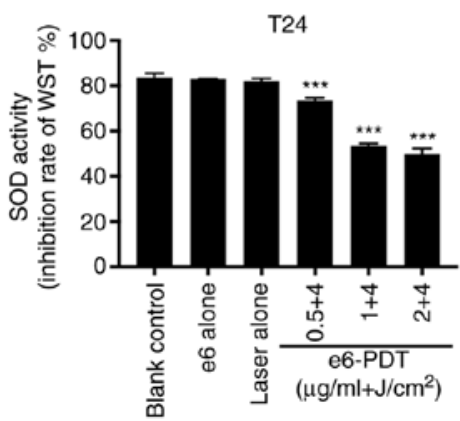

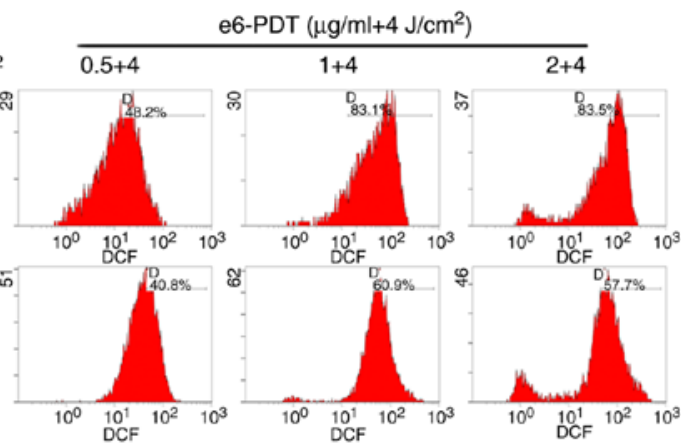

C

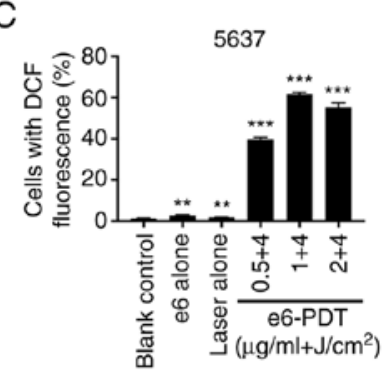

E

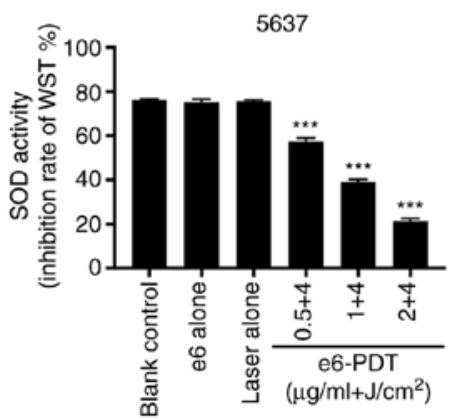

Figure 7. Detection of ROS and SOD in bladder cancer cells following e6-PDT. (A) DCFH-DA reagent was used to measure the production of intracellular ROS following e6-PDT. Cells with DCF fluorescence were examined with flow cytometry. (B and C) Quantification of ROS generated in T24 and 5637 cells $(n=3)$. (D and E) SOD activity of T24 and 5637 cells following e6-PDT was determined using a SOD Assay Kit-WST (n=3). The inhibition rate of WST reflects the activity of SOD. ${ }^{* *} \mathrm{P}<0.01$ and ${ }^{* * *} \mathrm{P}<0.001$ vs. blank control group. ROS, reactive oxygen species; SOD, superoxide dismutase; e6-PDT, chlorophyllin e6-mediated photodynamic therapy; DCFH-DA, 2',7'-dichlorofluorescein diacetate; WST, Water-Soluble Tetrazolium.

Similar results were obtained in T24 and 5637 cells. Thus, the results revealed that the increased ROS generation may be due to the reduction of SOD activity.

\section{Discussion}

The present study evaluated the photo-cytotoxicity of chlorophyllin e6-mediated PDT in monolayer cells and MCTS models of T24 and 5637 human bladder cancer cells, including cellular morphological and functional alterations. In addition, the underlying mechanisms of e6-PDT in treating bladder cancer were observed.

The functional mechanisms of PDT depend on 3 necessary components, including the PS, light source and oxygen. None of these have evident toxicity alone, but once combined, they can cause a photochemical reaction and subsequently destroy cells (11). The PS is the most critical factor, and the development of an optimal PS is extremely urgent and meaningful for utilizing effective PDT. It has been reported that some chlorophyll derivatives can be used as PSs for PDT and have demonstrated effective inhibition in tumor cell growth. For instance, a chlorophyll catabolite has been demonstrated to be a PS for PDT in pancreatic and liver cancer cells (30). Furthermore, the predominant ingredient of the silkworm chlorophyll derivative, 10-hydroxypheophytin A, exhibits excellent potential as a PS (31). The present study reports the phototoxic effects of chlorophyllin e6, a novel PS, on cancer cell proliferation and apoptosis in human bladder cancer cells. The results revealed that chlorophyllin e6 has a reliable and powerful photodynamic efficacy in treating T24 and 5637 cells.

Recently, MCTSs have emerged as an indispensable tool for new anticancer drug screening and therapeutic method testing, and are thought to offer an accurate prediction to optimize the pre-animal and pre-clinical selection of promising drugs and therapeutic strategies $(32,33)$. Several studies have revealed that the MCTS model is suitable for assessing the efficacy of PDT in cancer treatment $(34,35)$. Notably, using Zinc sulfophthalocyanine (ZnPcSmix)-mediated PDT to treat A549 cells, the effectiveness varies between monolayers and MCTSs. The $\mathrm{ZnPcSmix}-\mathrm{PDT}$ is more effective in monolayers and smaller spheroids $(250 \mu \mathrm{m})$ but not in larger spheroids $(500 \mu \mathrm{m})(34)$. The photocytotoxic effect of hypericin in 2D and 3D cultured RT-112 cells is also different. The effects observed in 3D 


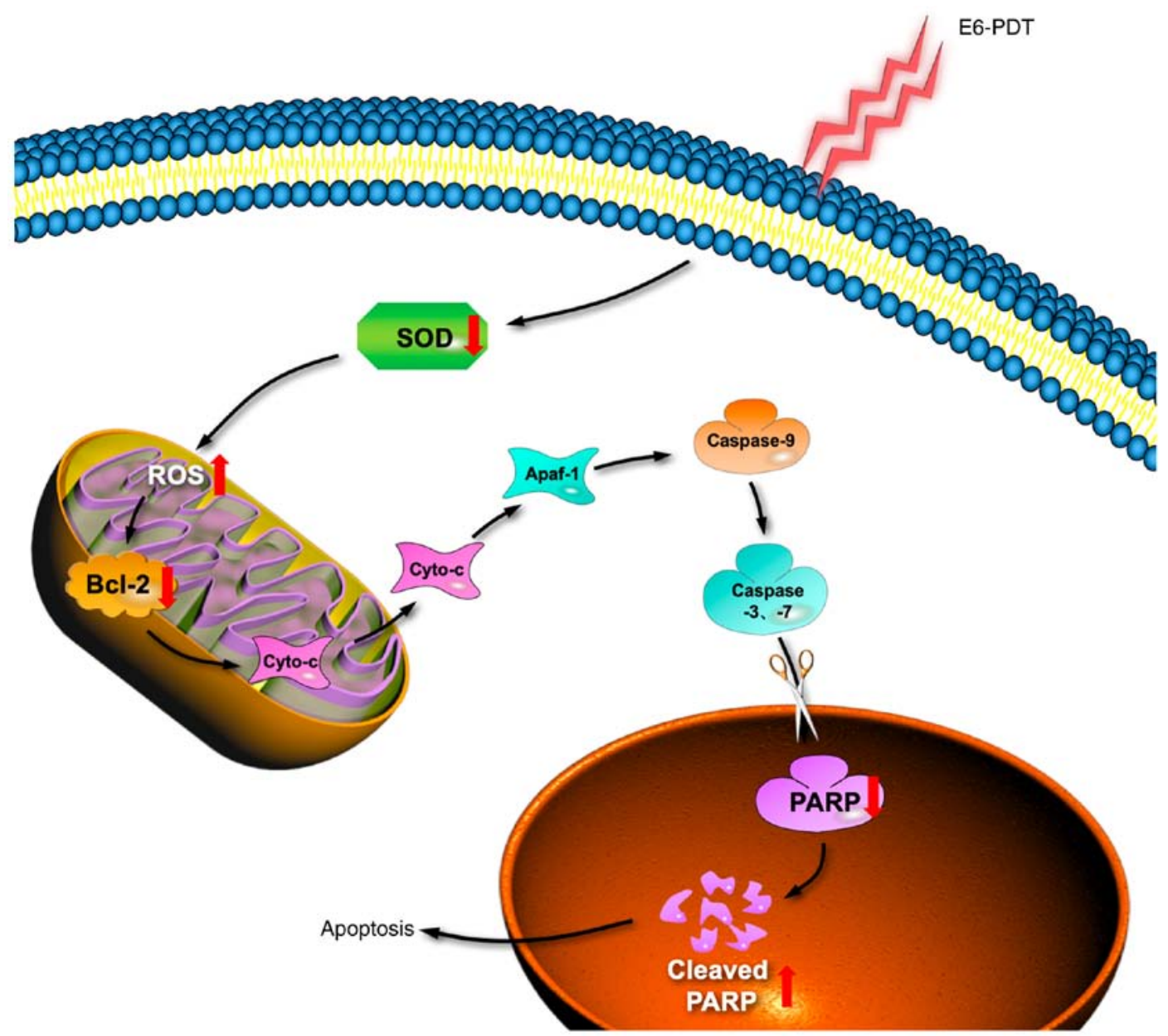

Figure 8. A schematic diagram of e6-PDT induces apoptosis in human bladder cancer cells. Following e6-PDT treatment, the activity of intracellular antioxidant enzyme SOD is reduced, which lead to the improvement of ROS generation in the mitochondria. An increased ROS activates pro-apoptotic proteins and inhibits an anti-apoptotic protein Bcl-2, leading to the release of Cyto-c from the mitochondria to the cytoplasm. Cyto-c along with Apaf-1 can cause the activation of caspase-9, which in turn activates the downstream effector caspases such as caspase- 3 and caspase-7. The activated caspase- 3 and caspase-7 further initiate the cleavage of downstream nuclear protein PARP, thus inducing cell apoptosis. e6-PDT, chlorophyllin e6-mediated photodynamic therapy; SOD, superoxide dismutase; ROS, reactive oxygen species; Bcl-2, B-cell lymphoma-2; Cyto-c, cytochrome $c$; Apaf-1, apoptosis activating factor-1; PARP, poly(adenosine diphosphate-ribose) polymerase.

cultured cells is markedly lower, demonstrating that $3 \mathrm{D}$ cell spheroids are more critical for preclinical evaluation of new PS efficacy (35). In the present study, a liquid overlay technique was utilized to culture T24 and 5637 MCTSs and to further investigate the e6-PDT effect on these MCTS models. This treatment process was particularly similar to the clinical intravesical application of PDT, which provided more reliable outcomes than monolayer cells. These results demonstrate that e6-PDT induces marked inhibition of cell viability in spheroid models at a suitable concentration of chlorophyllin e 6 and light energy $\left(10 \mu \mathrm{g} / \mathrm{ml}+8 \mathrm{~J} / \mathrm{cm}^{2}\right)$. Furthermore, the MCTSs demonstrated stronger resistance to e6-PDT when compared with their corresponding monolayer cells, which is consistent with previous studies $(34,35)$. These results suggest that chlorophyllin e6 may be a potential PS for the clinical PDT of NMIBC.

Despite significant progress in diagnosis strategies and therapies, $90 \%$ of mortalities associated with patients with cancer are due to cancer metastasis (36). Therefore, preventing the metastasis of cancer cells is a major aim of cancer treatment. In the present study, the effect of e6-PDT on blander cell migration and invasion was assessed. Notably, e6-PDT was revealed to affect the migration and invasion capacities of T24 and 5637 cells in a chlorophyllin e6 dose-dependent manner. These results indicated that e6-PDT may be a powerful tool in the inhibition of cell metastasis.

Apoptosis is generally considered to be the dominant type of cell death in the PDT procedure (11). The present study observed typical apoptotic cells with karyopyknosis, nuclear fragmentation, cell shrinkage, pseudopodia disappearance, chromatin condensation, mitochondria swelling, and cytoplasm vacuolization following e6-PDT. These apoptotic cells were also detected by flow cytometry with Annexin V-FITC/PI double staining. Furthermore, the expression levels of apoptosis-associated proteins PARP, cleaved PARP and Bcl-2 were altered following e6-PDT. The Bcl-2 family proteins are considered to be major regulators of cell apoptosis and they work through regulating the permeability of mitochondria (37). The pro-apoptotic proteins, including Bcl-2-associated death promoter, $\mathrm{BH} 3$ interacting-domain death agonist, BCL-2-associated $\mathrm{X}$ protein and Bim, can stimulate the release of cytochrome $c$, while the anti-apoptotic 
proteins, such as Bcl-2 and B-cell lymphoma-extra large, inhibit this process (38). The present study revealed a decrease in the expression of Bcl-2 and PARP proteins, along with an increase in cleaved PARP protein following e6-PDT. An instantaneous increase in poly(ADP-ribosyl)ation of nuclear proteins has been demonstrated to be involved in cell apoptosis, followed by cleavage of PARP, which is catalyzed by activated caspase-3 (39).

Emerging evidence has indicated that ROS serves a vital role in the function mechanism of PDT $(40,41)$. The light source excites PSs and initiates a series of photochemical reactions, which then lead to ROS generation (11). In addition, studies have revealed that cytotoxicity driven by PDT is associated with ROS production $(41,42)$. The present results suggest that the induction of cell apoptosis following e6-PDT is probably due to the increased level of ROS. To further investigate the reason for the ROS generation, the present study measured the activity of SOD in T24 and 5637 cells following e6-PDT. The results demonstrated a decrease in the activity of SOD in the e6-PDT groups compared with the blank control group in a chlorophyllin e6 dose-dependent manner. SOD is a naturally occurring antioxidant enzyme, which converts harmful superoxide radicals $\left(\mathrm{O}_{2}^{-}\right)$into normal oxygen molecular $\left(\mathrm{O}_{2}\right)$ or hydrogen peroxide $\left(\mathrm{H}_{2} \mathrm{O}_{2}\right)$ (43). Several studies have reported the correlation between the activity of SOD and ROS level. For example, $\mathrm{H}_{2} \mathrm{~S}$ activates SOD to decrease the levels of ROS in cardiomyocytes during ischemia-reperfusion (44). Safrole oxide can induce neuronal apoptosis through inhibition of SOD activity and improvement of ROS activity (45). Furthermore, the SOD inhibitors can greatly potentiate the cytotoxicity of PDT $(46,47)$. The present study indicated that e6-PDT inhibited the activity of SOD and generated the production of ROS. Increased ROS activates pro-apoptotic proteins and inhibits an anti-apoptotic protein Bcl-2, leading to the release of cytochrome $c$ from the mitochondria to the cytoplasm $(48,49)$. Cytochrome $c$ along with apoptosis activating factor- 1 can cause the activation of caspase- 9 , which in turn activates the downstream effector caspases such as caspase-3 and caspase-7 $(37,38,50)$. The activated caspase-3 and caspase- 7 further initiate the cleavage of downstream nuclear protein PARP, thus inducing cell apoptosis $(39,51,52)$.

In conclusion, the present study assessed the photodynamic effects of chlorophyllin e6 on monolayer cells and MCTS models of T24 and 5637 human bladder cancer cells. Based on these results, it was speculated that chlorophyllin e6 inhibits cell proliferation and metastasis by inhibiting the activity of SOD and producing ROS. A schematic illustration of the e6-PDT-induced cytotoxicity and cell apoptosis is revealed in Fig. 8. Chlorophyllin e6 may be a promising PS for the photodynamic treatment of human cancer. Further study will be valuable to learn the potential clinical application of e6-PDT in human bladder cancer.

\section{Acknowledgements}

The authors would like to thank Dr Hua Liu (Cancer Biotherapy Laboratory, Zhongshan Hospital, Fudan University) for providing the liquid overlay technique, Mr. Wencai Guan (Center Laboratory, Jinshan Hospital, Fudan University) for assistance with flow cytometry analysis.

\section{Funding}

The present study was supported by grants of the Shanghai Municipal Commission of Health and Family Planning (grant no. 201540372) and the Natural Science Foundation of Shanghai (grant no. 18ZR1405800).

\section{Availability of data and materials}

All data generated or analyzed during this study are included in this published article.

\section{Authors' contributions}

$\mathrm{ZZ}$ conducted experiments, data analyses, generated figures and was involved with manuscript preparation. ZS and ZM performed portions of the experiments and data analysis. YZ, GX, and GC designed the experiments. ZZ, GX and $\mathrm{GC}$ wrote the manuscript. All authors read and approved the manuscript.

\section{Ethics approval and consent to participate}

Not applicable.

\section{Patient consent for publication}

Not applicable.

\section{Competing interests}

The authors declare that they have no competing interests.

\section{References}

1. Antoni S, Ferlay J, Soerjomataram I, Znaor A, Jemal A and Bray F: Bladder cancer incidence and mortality: A global overview and recent trends. Eur Urol 71: 96-108, 2017.

2. Siegel RL, Miller KD and Jemal A: Cancer statistics, 2018. CA Cancer J Clin 68: 7-30, 2018.

3. Spiess PE, Agarwal N, Bangs R, Boorjian SA, Buyyounouski MK, Clark PE, Downs TM, Efstathiou JA, Flaig TW, Friedlander T, et al: Bladder cancer, version 5.2017, NCCN clinical practice guidelines in oncology. J Natl Compr Canc Netw 15: 1240-1267, 2017.

4. Kamat AM, Hahn NM, Efstathiou JA, Lerner SP, Malmstrom PU, Choi W, Guo CC, Lotan Y and Kassouf W: Bladder cancer. Lancet 388: 2796-2810, 2016.

5. Bohle A, Jocham D and Bock PR: Intravesical bacillus Calmette-Guerin versus mitomycin $C$ for superficial bladder cancer: A formal meta-analysis of comparative studies on recurrence and toxicity. J Urol 169: 90-95, 2003.

6. van Rhijn BW, Burger M, Lotan Y, Solsona E, Stief CG, Sylvester RJ, Witjes JA and Zlotta AR: Recurrence and progression of disease in non-muscle-invasive bladder cancer: From epidemiology to treatment strategy. Eur Urol 56: 430-442, 2009.

7. Botteman MF, Pashos CL, Redaelli A, Laskin B and Hauser R: The health economics of bladder cancer-A comprehensive review of the published literature. Pharmacoeconomics 21: 1315-1330, 2003.

8. Sievert KD, Amend B, Nagele U, Schilling D, Bedke J, Horstmann M, Hennenlotter J, Kruck S and Stenzl A: Economic aspects of bladder cancer: What are the benefits and costs? World J Urol 27: 295-300, 2009.

9. Gontero P, Bohle A, Malmstrom PU, O'Donnell MA, Oderda M, Sylvester R and Witjes F: The role of bacillus Calmette-Guérin in the treatment of non-muscle-invasive bladder cancer. Eur Urol 57: 410-429, 2010. 
10. Triesscheijn M,Baas P,Schellens JH and StewartFA: Photodynamic therapy in oncology. Oncologist 11: 1034-1044, 2006.

11. Agostinis P, Berg K, Cengel KA, Foster TH, Girotti AW, Gollnick SO, Hahn SM, Hamblin MR, Juzeniene A, Kessel D, et al: Photodynamic therapy of cancer: An update. CA Cancer J Clin 61: 250-281, 2011.

12. Robertson CA, Evans DH and Abrahamse H: Photodynamic therapy (PDT): A short review on cellular mechanisms and cancer research applications for PDT. J Photochem Photobiol B 96: 1-8, 2009.

13. Kapinova A, Stefanicka $\mathrm{P}$, Kubatka $\mathrm{P}$, Zubor $\mathrm{P}$, Uramova $\mathrm{S}$, Kello M, Mojzis J, Blahutova D, Qaradakhi T, Zulli A, et al: Are plant-based functional foods better choice against cancer than single phytochemicals? A critical review of current breast cancer research. Biomed Pharmacother 96: 1465-1477, 2017.

14. Eghbaliferiz S and Iranshahi M: Prooxidant activity of polyphenols, flavonoids, anthocyanins and carotenoids: Updated review of mechanisms and catalyzing metals. Phytother Res 30: $1379-1391,2016$

15. Abrahamse $\mathrm{H}$ and Hamblin MR: New photosensitizers for photodynamic therapy. Biochem J 473: 347-364, 2016.

16. Benov L: Photodynamic therapy: Current status and future directions. Med Princ Pract 1 (Suppl 24): S14-S28, 2015.

17. Zhang Q, Li ZH, Li YY, Shi SJ, Zhou SW, Fu YY, Zhang Q, Yang X, Fu RQ and Lu LC: Hypericin-photodynamic therapy induces human umbilical vein endothelial cell apoptosis. Sci Rep 5: 18398, 2015.

18. Bown SG, Rogowska AZ, Whitelaw DE, Lees WR, Lovat LB, Ripley P, Jones L, Wyld P, Gillams A and Hatfield AW: Photodynamic therapy for cancer of the pancreas. Gut 50: 549-557, 2002

19. Lou PJ, Jager HR, Jones L, Theodossy T, Bown SG and Hopper C: Interstitial photodynamic therapy as salvage treatment for recurrent head and neck cancer. Br J Cancer 91: 441-446, 2004.

20. Filonenko EV, Kaprin AD, Alekseev BY, Apolikhin OI, Slovokhodov EK, Ivanova-Radkevich VI and Urlova AN 5-Aminolevulinic acid in intraoperative photodynamic therapy of bladder cancer (results of multicenter trial). Photodiagnosis Photodyn Ther 16: 106-109, 2016.

21. Azzouzi AR, Vincendeau S, Barret E, Cicco A, Kleinclauss F, van der Poel HG, Stief CG, Rassweiler J, Salomon G, Solsona E, et al: Padeliporfin vascular-targeted photodynamic therapy versus active surveillance in men with low-risk prostate cancer (CLIN1001 PCM301): An open-label, phase 3, randomised controlled trial. Lancet Oncol 18: 181-191, 2017.

22. Walther MM, Delaney TF, Smith PD, Friauf WS, Thomas GF Shawker TH, Vargas MP, Choyke PL, Linehan WM, Abraham EH, et al: Phase I trial of photodynamic therapy in the treatment of recurrent superficial transitional cell carcinoma of the bladder. Urology 50: 199-206, 1997.

23. Skyrme RJ, French AJ, Datta SN, Allman R, Mason MD and Matthews PN: A phase-1 study of sequential mitomycin C and 5-aminolaevulinic acid-mediated photodynamic therapy in recurrent superficial bladder carcinoma. BJU Int 95: 1206-1210, 2005.

24. Bader MJ, Stepp H, Beyer W, Pongratz T, Sroka R, Kriegmair M, Zaak D, Welschof M, Tilki D, Stief CG, et al: Photodynamic therapy of bladder cancer-a phase I study using hexaminolevulinate (HAL). Urol Oncol 31: 1178-1183, 2013.

25. Li B, Wu Z,Li W, Jia G, Lu J, Fang J and Chen G: Chlorophyllin e4 is a novel photosensitizer against human bladder cancer cells. Oncol Rep 27: 1455-1460, 2012.

26. Nath S and Devi GR: Three-dimensional culture systems in cancer research: Focus on tumor spheroid model. Pharmacol Ther 163: 94-108, 2016.

27. Edmondson R, Broglie JJ, Adcock AF and Yang L: Three-dimensional cell culture systems and their applications in drug discovery and cell-based biosensors. Assay Drug Dev Technol 12: 207-218, 2014.

28. Costa EC, Moreira AF, de Melo-Diogo D, Gaspar VM, Carvalho MP and Correia IJ: 3D tumor spheroids: An overview on the tools and techniques used for their analysis. Biotechnol Adv 34: 1427-1441, 2016

29. Kapuscinski J and Szer W: Interactions of 4',6-diamidine-2phenylindole with synthetic polynucleotides. Nucleic Acids Res 6: 3519-3534, 1979.

30. Xodo LE, Rapozzi V, Zacchigna M, Drioli S and Zorzet S: The chlorophyll catabolite pheophorbide a as a photosensitizer for the photodynamic therapy. Curr Med Chem 19: 799-807, 2012

31. Dai R, Shoemaker R, Farrens D, Han MJ, Kim CS and Song PS: Characterization of silkworm chlorophyll metabolites as an active photosensitizer for photodynamic therapy. J Nat Prod 55: $1241-1251,1992$
32. Hirschhaeuser F, Menne H, Dittfeld C, West J, Mueller-Klieser W and Kunz-Schughart LA: Multicellular tumor spheroids: An underestimated tool is catching up again. J Biotechnol 148: 3-15, 2010.

33. Friedrich J, Seidel C, Ebner R and Kunz-Schughart LA Spheroid-based drug screen: Considerations and practical approach. Nat Protoc 4: 309-324, 2009.

34. Manoto SL, Houreld NN and Abrahamse H: Resistance of lung cancer cells grown as multicellular tumour spheroids to zinc sulfophthalocyanine photosensitization. Int J Mol Sci 16: 10185-10200, 2015.

35. Huygens A, Huyghe D, Bormans G, Verbruggen A, Kamuhabwa AR, Roskams T and de Witte PA: Accumulation and photocytotoxicity of hypericin and analogs in two- and three-dimensional cultures of transitional cell carcinoma cells. Photochem Photobiol 78: 607-614, 2003

36. Chaffer CL and Weinberg RA: A Perspective on cancer cell metastasis. Science 331: 1559-1564, 2011

37. Youle RJ and Strasser A: The BCL-2 protein family: Opposing activities that mediate cell death. Nat Rev Mol Cell Biol 9: 47-59, 2008.

38. Kluck RM, BossyWetzel E, Green DR and Newmeyer DD: The release of cytochrome $c$ from mitochondria: A primary site for Bcl-2 regulation of apoptosis. Science 275: 1132-1136, 1997.

39. Boulares AH, Yakovlev AG, Ivanova V, Stoica BA, Wang GP, Iyer $\mathrm{S}$ and Smulson M: Role of poly(ADP-ribose) polymerase (PARP) cleavage in apoptosis. Caspase 3-resistant PARP mutant increases rates of apoptosis in transfected cells. J Biol Chem 274: 22932-22940, 1999.

40. Zhou Z, Song J, Nie L and Chen X: Reactive oxygen species generating systems meeting challenges of photodynamic cancer therapy. Chem Soc Rev 45: 6597-6626, 2016.

41. Lam M, Oleinick NL and Nieminen AL: Photodynamic therapy-induced apoptosis in epidermoid carcinoma cells. Reactive oxygen species and mitochondrial inner membrane permeabilization. J Biol Chem 276: 47379-47386, 2001.

42. Kim CH, Chung CW, Choi KH, Yoo JJ, Kim DH, Jeong YI and Kang DH: Effect of 5-aminolevulinic acid-based photodynamic therapy via reactive oxygen species in human cholangiocarcinoma cells. Int J Nanomedicine 6: 1357-1363, 2011.

43. Abreu IA and Cabelli DE: Superoxide dismutases-a review of the metal-associated mechanistic variations. Biochim Biophys Acta 1804: 263-274, 2010.

44. Sun WH, Liu F, Chen Y and Zhu YC: Hydrogen sulfide decreases the levels of ROS by inhibiting mitochondrial complex IV and increasing SOD activities in cardiomyocytes under ischemia/reperfusion. Biochem Biophys Res Commun 421: 164-169, 2012.

45. Su L, Zhao B, Lv X, Wang N, Zhao J, Zhang S and Miao J: Safrole oxide induces neuronal apoptosis through inhibition of integrin beta 4/SOD activity and elevation of ROS/NADPH oxidase activity. Life Sci 80: 999-1006, 2007.

46. Golab J, Nowis D, Skrzycki M, Czeczot H, Baranczyk-Kuzma A, Wilczynski GM, Makowski M, Mroz P, Kozar K, Kaminski R, et al: Antitumor effects of photodynamic therapy are potentiated by 2-methoxyestradiol. A superoxide dismutase inhibitor. J Biol Chem 278: 407-414, 2003.

47. Kimani SG, Phillips JB, Bruce JI, MacRobert AJ and Golding JP: Antioxidant inhibitors potentiate the cytotoxicity of photodynamic therapy. Photochem Photobiol 88: 175-187, 2012.

48. Fleury C, Mignotte B and Vayssiere JL: Mitochondrial reactive oxygen species in cell death signaling. Biochimie 84: 131-141, 2002.

49. Redza-Dutordoir M and Averill-Bates DA: Activation of apoptosis signalling pathways by reactive oxygen species. Biochim Biophys Acta 1863: 2977-2992, 2016.

50. Yang J, Liu X, Bhalla K, Kim CN, Ibrado AM, Cai J, Peng TI, Jones DP and Wang X: Prevention of apoptosis by Bcl-2: Release of cytochrome $c$ from mitochondria blocked. Science 275: 1129-1132, 1997.

51. Ruemmele FM, Dionne S, Qureshi I, Sarma DS, Levy E and Seidman EG: Butyrate mediates Caco-2 cell apoptosis via up-regulation of pro-apoptotic BAK and inducing caspase-3 mediated cleavage of poly-(ADP-ribose) polymerase (PARP). Cell Death Differ 6: 729-735, 1999.

52. Tyagi A, Agarwal C, Harrison G, Glode LM and Agarwal R: Silibinin causes cell cycle arrest and apoptosis in human bladder transitional cell carcinoma cells by regulating CDKI-CDK-cyclin cascade, and caspase 3 and PARP cleavages. Carcinogenesis 25: $1711-1720,2004$

This work is licensed under a Creative Commons Attribution-NonCommercial-NoDerivatives 4.0 International (CC BY-NC-ND 4.0) License. 